\title{
How to run a large group teaching session
}

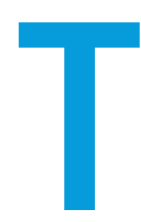

he most common form of large group teaching is the traditional lecture. For the purposes of this article, a large group is defined as anything involving more than 15 learners. At this size, many of the techniques that work for smaller groups, such as direct dialogue between the teacher and individual learners, either do not work at all or have more disadvantages than advantages. In recent years, large group teaching has fallen out of favour. Educational theories have emphasized the importance of learner-centred models that promote social interactions between teacher and students in a collaborative venture (Springer et al, 1999). Lectures have been seen as instructional but didactic, seeking to impart knowledge but lacking the structure to maximize deep learning through learner engagement. Few will not recognize the seeming futility of sitting in a large lecture theatre being spoken to by an expert rehearsing the content of a PowerPoint presentation.

Nevertheless, large group teaching and lectures continue to represent a significant proportion of teaching activities in medical schools. Undoubtedly, one of the major drivers is financial and logistical. Putting a single individual in front of 250 students to give a 1-hour lecture on a specific topic easily becomes the default position. Such large group teaching sessions appeal to the comfort zone of both teachers and students (Table 1) despite considerable disadvantages.

In many scenarios, large group teaching is not the best option but there may be little alternative as a result of institutional or structural issues. Examples include being asked to give a lecture to clinical students who are on placement and can only be brought together at a single time and place, or at a large conference.

\footnotetext{
Professor John Alcolado, Deputy Head of

School, University of Nottingham Medical

School, Royal Derby Hospital,

Derby DE22 3DT

(John.Alcolado@nottingham.ac.uk)
}

\section{Preparation and planning}

Large group teaching lends itself to the transmission of structured expert knowledge (Matheson, 2008). You should carefully consider the needs of the learners. A common mistake is to pitch the teaching at the wrong level. Never agree to give a teaching session unless you know the expected learning outcomes. If none are available, start by formulating your own. Consult curriculum maps or speak to course organizers so that you understand the prior learning of the audience. Ideally, speak to some of the intended learners and find out what they know about the subject and what they would like to learn. One of the disadvantages of

\section{Table 1. Advantages and disadvantages of large group teaching sessions}

\begin{tabular}{|l|l|}
\hline Advantages & $\begin{array}{l}\text { Standardized information can } \\
\text { be delivered to all students }\end{array}$ \\
\hline $\begin{array}{l}\text { All students receive the same } \\
\text { experience }\end{array}$ \\
\hline $\begin{array}{l}\text { Cost-effective in terms of } \\
\text { teacher resource }\end{array}$ \\
\hline Easier to timetable \\
\hline Easier to video for future use \\
\hline $\begin{array}{l}\text { Less disadvantage to students } \\
\text { who find it difficult to perform } \\
\text { in small groups }\end{array}$ \\
\hline $\begin{array}{l}\text { Difficult to adjust content to } \\
\text { individual student needs }\end{array}$ \\
\hline $\begin{array}{l}\text { A poor session impacts a large } \\
\text { number of students }\end{array}$ \\
\hline $\begin{array}{l}\text { Students become passive } \\
\text { and mistake attendance for } \\
\text { learning }\end{array}$ \\
\hline Disadvantageacher or student miss the \\
\hline $\begin{array}{l}\text { If tession, difficult to repeat } \\
\text { Teaching can lack spontaneity }\end{array}$ \\
\hline $\begin{array}{l}\text { Difficult to model behaviours } \\
\text { and attitudes }\end{array}$ \\
\hline
\end{tabular}

large groups is that they contain people with a mixed level of background knowledge. Be aware of this and aim to give something to each member of audience. Specifically ask yourself: 'would a novice understand what I am saying and would an expert learn something new?'

Estimate the likely size of the group. It will be disheartening if you expect an audience of hundreds but only 20 turn up, and it will be nerve-racking if the opposite occurs. Know about the in-house style; are questions left to the end or is there a culture of asking questions throughout? Although seemingly self-evident, many teachers do not give adequate thought to the timing of their sessions. It is generally better to plan a shorter presentation than the actual time allocated. This will allow time for questions, and unforeseen issues such as the previous lecturer finishing late. Familiarize yourself with the venue and the IT. Many universities now ask lecturers to upload their presentations to an online learning platform a few days before their teaching session but always have a copy of your presentation on an external drive in case the system crashes when you are about to start. Although most information has migrated online, consider whether you also want to prepare some hard copy hand-outs to give to the learners summarizing key points.

The vast majority of teachers and learners will expect a PowerPoint presentation during a large group teaching session. It is certainly a very useful programme, but there are many pitfalls. Invest some time in learning how to produce a good PowerPoint presentation (Harolds, 2012). You may be expected to use a house style, for example, a specific template or corporate background. Always use clear, large (at least 28 point) font with a light background and dark colour (blue or black are ideal). The previous approach of writing on acetates or chalkboards did have the advantage that students could see the material being built up and could be more engaged with the process. Modern whiteboards can 


\section{What They Don't Teach You At Medical School}

serve a similar purpose. Consider using QR codes that students can scan into their smart phones and link to additional online teaching resources. If your teaching session is going to be recorded, make sure you know in advance. Ideally, ask to see the recording so you can edit out any errors before it becomes available online.

Give some thought to the ambient lighting in the room. Low-level lighting tends to induce somnolence; generally only dim the lights to the extent required for the projection facilities to work well. Good quality projectors work well in all but direct sunlight. It is also useful to alter the lighting during different sections of your lecture, for example, by making the room even brighter to cue a particularly important point.

\section{The art of large group teaching}

Your primary aim should be to inspire learners, not just to deliver factual information. Your lecture should not be like reading a textbook or reciting the content of your presentation. You should impart a real passion for the subject. The accepted wisdom is always to start by listing the learning outcomes and an outline of your session, so that students know where they are going. However, this can become formulaic and it can be powerful to start with a dramatic clinical vignette or scenario that immediately grabs the attention. Learners are strongly motivated by examinations and assessments, so it is generally unhelpful to reinforce this further by telling students your session is important because it is likely to appear in a subsequent test.

The 'flipped classroom' model (Chen et al, 2017 ) is one in which you contact learners before your session and provide them with the learning outcomes and learning materials, including your presentation or a video. They are expected to work through the material and then attend the teaching session specifically to clarify difficult areas. It is possible to set a formative assessment before the session so the teacher can concentrate on topics the learners have not understood fully.

Passivity of learners is a major risk during a large teaching session and so you should $\exists$ strive to introduce interactivity. A common way of achieving this is to break up the audience into smaller groups to discuss a question or topic. An efficient way of doing this is by asking learners to speak to the person immediately to next to them for a few minutes, and then to ask for each row of students to feedback their discussions to the entire group. Asking questions to the entire group can work, but risks engaging only the 'usual suspects' who always tend to answer and may alienate others in the group. When asking questions, avoid those that require a simple factual response in favour of those that encourage critical thinking.

A variety of apps can be used to allow students to ask questions or reply during teaching sessions (e.g. www.meetoo.com/ why-meetoo/for-education) or systems can be used to capture 'votes' on particular topics that have been raised. This allows the teacher to focus on areas that have been poorly understood. It may also improve the engagement of learners who would not be confident enough to speak out in a large group.

There are a number of critical stages in the delivery of large group teaching that merit special attention. Starting a session can be challenging, especially if latecomers are drifting in or the room is very noisy. Generally dimming the lights and putting up the first slide will work, but not always. Other techniques include playing a short clip of loud music, or simply standing in silence and staring at the audience. This generally works better than trying to shout over the background conversations. Think about a policy to deal with latecomers. One option is to direct them to sit in the front rows as they arrive, since these are usually left vacant. There is little to be gained by publicly humiliating them since they may have a good reason for their tardiness and the aim is to continue the session with the least interruption. Disruptive students are rarely a problem in an adult learning environment. If the situation does arise, deal with it politely but firmly, e.g. 'Background noise travels in this room and I am finding it difficult to carry on so I will stop until there is silence. If there is something important you need to discuss, please don't feel embarrassed to leave the room so we can carry on.'

\section{Feedback, evaluation and reflection}

It may be difficult or inappropriate to give feedback to individual students during or after a large group teaching session, but some techniques can be useful. Congratulate students who ask good questions or raise

\section{KEY POINTS}

Large group teaching can be cost-effective and efficient.

- Be inspirational - what value are you adding to a textbook or the slides?

- Be clear what the learning objectives are.

- Prepare carefully - what would you do if the IT system crashed?

- Encourage interactivity by breaking up large groups.

- Consider using the 'flipped classroom' model.

- Reflect on regular evaluation of your teaching.

interesting points. Some university online teaching platforms will allow you to send out a group message to all participants after the session to thank them for their contributions or to encourage further learning in areas where you feel it may be required.

Ask students to evaluate your teaching on a regular basis. There may be institutional mechanisms by which learners are asked to fill out evaluation forms at the end of teaching sessions but response rates can be poor. One useful technique is to pass around two different coloured post-it notes to all learners just before the end of your session and ask them to write down a good thing about your session on one and something that could have been done better on the other, and then to drop them into separate boxes on the way out. This will give you anonymous immediate evaluation. It is impossible to improve as a teacher unless you reflect on the evaluation you collect. BJHM

Conflict of interest: none.

Chen F, Lui AM, Martinelli SM (2017) A systematic review of the effectiveness of flipped classrooms in medical education. Med Educ 51(6): 585-597. https://doi.org/10.1111/medu.13272

Harolds JA (2012) Tips for giving a memorable presentation, Part IV: using and composing PowerPoint slides. Clin Nucl Med 37(10): 977-980. https://doi.org/10.1097/ RLU.0b013e3182614219

Matheson C (2008) The educational value and effectiveness of lectures. Clin Teach 5(4): 218-221. https://doi.org/10.1111/j.1743498X.2008.00238.x

Springer L, Stanne ME, Donovan SS (1999) Effects of small group learning on undergraduates in science, mathematics, engineering, and technology: a meta-analysis. Rev Educ Res 69(1): 21-51. https://doi. org/10.3102/00346543069001021 